\title{
A method to identify individually physiological response differences to heat exposure using Comprehensive Deviation Coefficient (CDC)
}

Article

Accepted Version

Creative Commons: Attribution-Noncommercial-No Derivative Works 4.0

Li, Y., Du, C., Yao, R., Li, G. and Li, B. (2020) A method to identify individually physiological response differences to heat exposure using Comprehensive Deviation Coefficient (CDC). Energy and Buildings, 217. 110003. ISSN 03787788 doi: https://doi.org/10.1016/j.enbuild.2020.110003 Available at https://centaur.reading.ac.uk/90642/

It is advisable to refer to the publisher's version if you intend to cite from the work. See Guidance on citing.

Published version at: http://dx.doi.org/10.1016/j.enbuild.2020.110003

To link to this article DOI: http://dx.doi.org/10.1016/j.enbuild.2020.110003

All outputs in CentAUR are protected by Intellectual Property Rights law, including copyright law. Copyright and IPR is retained by the creators or other copyright holders. Terms and conditions for use of this material are defined in the End User Agreement. 


\section{CentAUR}

Central Archive at the University of Reading

Reading's research outputs online 


\title{
A method to identify individually physiological response differences to heat exposure using Comprehensive Deviation Coefficient (CDC)
}

\author{
Yongqiang Li, Chenqiu Du, Runming Yao, Guoqing Li, Baizhan Li
}

\section{Abstract}

With increasing global warming, a method to identify individual heat exposure risk and conduct interventions is essential, in order to mitigate impacts of extreme climates on people's health. This paper aims to examine the differences of individual's physiological response in hot environments and consequently proposes a personal-based method to identify potentially vulnerable populations with high risk. A heat exposure experiment was carried out in a climate chamber to build datasets, with nine conditions combining air temperature $\left(35^{\circ} \mathrm{C} / 38^{\circ} \mathrm{C} / 40^{\circ} \mathrm{C}\right)$ and relative humidity $(25 \% / 40 \% / 60 \%)$. The rectal temperature (Tre), skin temperature (Tsk) and heart rate (HR) of 10 subjects were monitored. Data were analyzed using multiple-dimensional metrics of average deviation(AD), coefficient of variation(CV) and skewness(SKEW). The study introduced the Moment of Inertia (MI) and the Simulated Mass System (MS) in a multidimensional coordinate system and developed a Comprehensive Deviation Coefficient (CDC) method. Using various combinations of $A D / C V / S K E W$, the values of $C D C_{T r e}, C D C_{T s k}, C D C_{H R}$ were calculated; the high-risk thermal environment $\left(40^{\circ} \mathrm{C} / 60 \%\right)$ and subject were thus identified. The proposed CDC method enables to distinguish the individual's physiological response differences, under different hot environments and personal characteristics. The equations in this method can be programed in computer and integrated with smart sensor technology, contributing to identify the high-risk environments and provide precautions for susceptible populations, to mitigate the heat exposure hazards on people' health and safety.

\section{Keywords}

Hot environment; Physiological response; Individual difference; Multidimensional metrics; Comprehensive Deviation Coefficient(CDC) method; Heat stress risk. 


\section{Nomenclature}

\begin{tabular}{|c|c|c|c|}
\hline AD & average deviation & $\mathrm{HR}_{\mathrm{t}}$ & total heart rate (beat/minute) \\
\hline ADu & DuBois body surface area $\left(\mathrm{m}^{2}\right)$ & $\mathrm{HR}_{\mathrm{s}}$ & $\begin{array}{l}\text { static exertion heart rate } \\
\text { (beat/minute) }\end{array}$ \\
\hline $\begin{array}{l}A D_{T r e, i n, i} \\
A D_{T s k, i n, i} \\
A D_{H R, i n, i}\end{array}$ & $\begin{array}{c}\text { AD of Tre/ Tsk/ HR under the } \\
\text { influence of internal personal } \\
\text { difference }\end{array}$ & $H R_{T}$ & $\begin{array}{l}\text { thermal strain heart rate } \\
\text { (beat/minute) }\end{array}$ \\
\hline $\begin{array}{l}A D_{\text {Tre,out,i }} \\
A D_{\text {Tsk,out,i }} \\
A D_{\text {HR,out,i }}\end{array}$ & $\begin{array}{c}\text { AD of Tre/ Tsk/ HR under the } \\
\text { influence of external hot } \\
\text { environments }\end{array}$ & MI & moment of inertia $\left(\mathrm{kg} \bullet \mathrm{m}^{2}\right)$ \\
\hline AV & average value & $\mathbf{M S}_{\mathrm{i}}$ & simulated mass system \\
\hline $\begin{array}{l}A V_{\text {Tre,in,i }} \\
A V_{\text {Tsk,in,i }} \\
A V_{H R, i n, i}\end{array}$ & $\begin{array}{c}\text { AV of Tre/ Tsk/ HR under the } \\
\text { influence of internal personal } \\
\text { difference }\end{array}$ & $\mathbf{n}$ & size of the sample \\
\hline $\begin{array}{l}A V_{\text {Tre,out,i }} \\
A V_{\text {Tsk,out,i }} \\
A V_{H R, \text { out,i }}\end{array}$ & $\begin{array}{c}\text { AV of Tre/ Tsk/ HR under the } \\
\text { influence of external } \\
\text { environment difference }\end{array}$ & Nor & normalization process \\
\hline$C_{m j}$ & $\begin{array}{c}\text { characteristic parameter of } \\
\text { "Vj" under the influence of " } \mathrm{fi} \text { " } \\
(\mathrm{i}=\mathrm{m})\end{array}$ & SD & standard deviation \\
\hline$C_{k}$ & $\begin{array}{c}\text { characteristic parameter of } \\
\text { "Vj" (AV/ AD/ CV/ SKEW, } k \geq 1)\end{array}$ & SKEW & skewness \\
\hline $\mathrm{C}_{\mathrm{s}, \mathrm{fi}}$ & $\begin{array}{l}\text { characteristic parameter C } \\
\text { under the influence of "fi" }\end{array}$ & $\begin{array}{l}\text { SKEW }_{\text {Tre,in,i }} \\
\text { SKEW }_{\text {Tsk,in,i }} \\
\text { SKEW }_{H R, i n, i} \\
\end{array}$ & $\begin{array}{l}\text { SKEW of Tre/ Tsk/ HR under the } \\
\text { influence of internal personal } \\
\text { difference }\end{array}$ \\
\hline CV & $\begin{array}{l}\text { coefficient of variation } \\
\text { (dimensionless) }\end{array}$ & $\begin{array}{l}\text { SKEW } \\
\text { Tre,out,i } \\
\text { SKEW }_{\text {Tsk,out,i }} \\
\text { SKEW }_{\text {HR,out,i }}\end{array}$ & $\begin{array}{l}\text { SKEW of Tre/ Tsk/ HR under the } \\
\text { influence of external environment } \\
\text { difference }\end{array}$ \\
\hline $\begin{array}{l}C V_{\text {Tre,in,i }} \\
C V_{\text {Tsk,in,i }} \\
C V_{H R, i n, i}\end{array}$ & $\begin{array}{c}\text { CV of Tre/ Tsk/ HR under the } \\
\text { influence of internal personal } \\
\text { difference }\end{array}$ & Sum & summation \\
\hline $\begin{array}{l}C V_{\text {Tre,out,i }} \\
\mathrm{CV}_{\text {Tsk,out,i }} \\
\mathrm{CV}_{\mathrm{HR}, \text { out }, \mathrm{i}}\end{array}$ & $\begin{array}{l}\text { CV of Tre/ Tsk/ HR under the } \\
\text { influence of external } \\
\text { environment difference }\end{array}$ & Tre & rectal temperature $\left({ }^{\circ} \mathrm{C}\right)$ \\
\hline fi & $\begin{array}{l}\text { variable factors affecting } \mathrm{W} \\
\text { (dimensionless, } \mathrm{i}=1,2,3 \ldots \mathrm{m} \text { ) }\end{array}$ & Tsk & skin temperature $\left({ }^{\circ} \mathrm{C}\right)$ \\
\hline HR & heart rate (beat/minute) & $\mathbf{V j}$ & $\begin{array}{l}\text { variation of W caused by "fi" } \\
\text { (dimensionless, } j=1,2,3 \ldots n \text { ) }\end{array}$ \\
\hline $\mathrm{HR}_{\mathbf{0}}$ & $\begin{array}{c}\text { thermal neutrality heart rate } \\
\text { (beat/minute) }\end{array}$ & $\mathbf{W}$ & target parameter (as Tre/ Tsk/ HR) \\
\hline$H_{R_{e}}$ & $\begin{array}{l}\text { residual heart rate (beat/ } \\
\text { minute) }\end{array}$ & $\mathbf{W}_{\mathrm{fi}}$ & $\begin{array}{l}\text { target parameter W under the } \\
\text { influence of "fi" (as Tre/ Tsk/ HR) }\end{array}$ \\
\hline$H R_{M}$ & $\begin{array}{l}\text { metabolic heart rate (beat/ } \\
\text { minute) }\end{array}$ & $\mathbf{x}$ & $\begin{array}{l}\text { each sample of the target } \\
\text { parameter }\end{array}$ \\
\hline $\mathrm{HR}_{\mathrm{N}}$ & $\begin{array}{c}\text { emotion heart rate } \\
\text { (beat/minute) }\end{array}$ & $\Delta$ & $\begin{array}{l}\text { the comprehensive } \mathrm{MI} \\
\text { (dimensionless) }\end{array}$ \\
\hline
\end{tabular}




\begin{tabular}{c|c|c|l}
\hline PHS & predicted heat strain model & SWreq & Required sweat rate, $\mathrm{W} / \mathrm{m}^{2}$ \\
\hline HSI & $\begin{array}{c}\text { heat stress index } \\
\text { (dimensionless) }\end{array}$ & WBGT & wet bulb globe temperature $\left({ }^{\circ} \mathrm{C}\right)$ \\
\hline
\end{tabular}




\section{Introduction}

According to the newly issued report on the State of the Global Climate by World Meteorological Organization (WMO), the average global temperature for 2013-2017 was the highest compared to the recorded five-year averages before[1]. For example, in 2017, there was a Level 2 heatwave alert issued by the Public Health England(PHE) in England in June, with some areas reaching their highest temperatures since June 1976 [2]. Just over the past summer in 2019, Europe boiled in soaring temperatures and $40^{\circ} \mathrm{C}$ heatwave swept from south to north, especially in France[3]. The climate change and globe warming [4] further accompanied with the increased frequency and intensity of extreme heatwave events in many regions [5-6]. Exposures to such extreme heat conditions has led to heat stroke, heat exhaustion, heat cramps, and heat rashes [7]. Evidence from a large number of epidemiological studies[8-10] have revealed that the hot environments and extreme heatwaves aggravated the heat-related mortality and morbidity of populations, especially for cardiovascular and respiratory diseases, resulting in a more severe and widespread health risk impact[11-13]. A report in Lancet analyzed 74,225,200 deaths in various periods between 1985 and 2012 and concluded that extreme cold and hot temperatures were responsible for $0.86 \%$ (0.84\%-0.87\%) of total mortality[14]. In particular, excess mortalities of nearly 19,000 occurred during the 2003 European extreme heat event[15], especially in France inside of households (appropriately 50\%) [16]. After implementing the heat health action plans, for example, in Frankfurt, the excess mortality for the overall population in the heatwaves was decreased, comparing 2003 (77.8\%) to the following years (2006: 12\%, 2010: 22.7\%, 2015: 38.1\%)[17]. In fact, many at-risk populations are exposed to warm temperatures inside buildings. For example, in New York, almost $85 \%$ classified hyperthermia cases succumbed to heat in their own home [18]. In another tropic region, Huang[19] analyzed the heatwave events in 60 provinces in Thailand and also found that mild heatwaves were associated with greater cumulative effects on total and causespecific mortality, partly due to the protection awareness in extreme heatwave events.

In recent years, combined with the "The Belt and Road Initiative" development, China is experiencing a rapid urbanization and increased urban population. However, in the context of ongoing climate change, the magnitude of heatwave impacts increased by intensities and durations of the heatwaves, according to a study in 31 Chinese capital cities during 2007-2013[20]. In such cases, occupational heat exposure and injury risk for people, like workers in construction sites, has been increasingly a focused question so that how to mitigate the impacts due to heat exposure is among the most urgent of people' needs. According to the US Census of Fatal Occupational Injuries[21], workers account for $36 \%$ of the heated-related mortalities from 2003 to 2008. In China, quite a number of occupational workers are involved in physically demanding tasks under hot environments both indoors and outdoors. In such contexts, a concerted effort must be made to promote the health and safety for people, develop targeted protection policies and managements, and minimize the productivity/performance loss.

Exposing to high temperature would cause various physiological strains (e.g. increase body and skin temperatures, metabolic rates, sweating, heart rates), deteriorate performance and productivity, increase the incident rates of health-related illness[22, 23]. To prevent body heat strain, a series of practice guidelines/strategies, including permitted work, recover time, work shelters[24], improving thermal environments and ventilation [25] have been studied; more than 100 heat stress indices and models have been developed [26]. Some more complex models, like the required sweat rate ( $\mathrm{SW}_{\text {req }}$ ) and predicted heat strain (PHS) model, were subsequently proposed and adopted in ISO7933 standard[27], based on the human heat production and dissipation mechanism[28]. However, they were built by an averaging method [29] and were representative for 
an average European people [30]. The prediction performance has been challenged with various deviations in applications [31, 32]. It is known that human heat stress results from a combination of factors, including environmental conditions, work demands, and individual characteristics[33, 34]. The differences significantly exist among individuals that make the rational models less valid in practical prediction. Therefore, a method to evaluate the individual differences is of importance, in order to identify the individuals who are vulnerable with increasing health risks in hot environments and to provide early interventions for people, as well as management for supervisors.

However, the inter-individual variability is evident, due to the characteristics of different physiological indices[35]. Heat causing mild stimulus in one person may induce heat-related risk in another [36]. Study from Racinais et al. [37] found a high inter-individual variation in the adaptive responses to a 6-day heat acclimatization experiment (e.g. change in plasma volume from - $10 \%$ to +20\%) with apparent "responders" and "non-responders"; the individual differences were also reported by the authors in another experiment with two-week acclimatization interventions [38]. Recently, Yi et al. [39] established an artificial neural networks method to predict the perception rating of perceived exertion for construction workers and developed an early-warning system against hot and humid climates, based on a database containing 550 sets of synchronized workrelated, environmental, and personal data. Chan et al. [40,41] conducted a multiple regression to relate human physiological responses to environmental, worked-related and personal factors in hot environments. However, in most cases, human heat stress is not linear to these influencing factors; knowledge with respect to risk identification at individual levels remains incompletely understood [30].

To sum up, it poses challenge to use readily-available measurements of individuals to predict different thermal responses accurately [30] and promote protections more effectively[42]. To this end, this study aims to propose a new method to evaluate the individual differences during heat exposures. This is achieved through introducing a multidimensional model, and a Comprehensive Deviation Coefficient(CDC). The method enables to evaluate the degrees of physiological responses of different individuals regarding to environmental and personal parameters, which is expected to fill the knowledge gap of identifying the harsh environments and vulnerable populations during heat exposure, and benefit for targeted protection policies and interventions for people' health and thermal safety.

\section{Method of Comprehensive Deviation Coefficient (CDC) evaluation}

\subsection{Evaluation indices in multiple dimensions}

The human physiological strain in hot environments depends on both individual factors (e.g. health status, heat tolerance, sweat rate, regulation degree) and environmental factors (e.g. physical parameters, exposure time). The triggered variability in typical physiological indices (e.g., rectal temperature(Tre), skin temperature(Tsk), heart rate(HR) $[30,43,44])$ contain both absolute changes in the original dimension, like maximum, minimum, mean, standard deviation, and the relative changes in multiple dimensions, like variability, skewness.

(1) Absolute Variation (AD)

From the measurement point of view, both the system errors and random errors affect the average value(AV) and standard deviation(SD). In contrast, the $A D$ takes $A V$ as reference system and is less susceptibly affected by random errors compared to the SD. The SD is based on the variance by 
squaring while $A D$ does the logic judgment for data fluctuation[45]. Therefore, the $A D$ is introduced, as shown in Equation (1).

$$
A D=\frac{\sum|x-A V|}{n}
$$

\section{(2) Coefficient of Variation (CV)}

The $\mathrm{CV}$ is a dimensionless statistical index to measure the data dispersion correlating to the $\mathrm{AV}$ $[46,47]$. Although some other statistics such as the quartiles and SD are commonly used to measure data variability, the $\mathrm{CV}$ takes advantage of cross-dimension analysis, which has been widely applied in biomedicine, environmental analysis, manufacturing, dynamics studies, etc. $[48,49]$. The CV can be calculated in Equation (2).

$$
C V=\frac{S D}{A V}
$$

\section{(3) Skewness (SKEW)}

The SKEW is adopted to measure the degree of data skewing. The SKEW measures the asymmetry distribution of data, reflecting the third order central moment of variables. The SKEW for a normal distribution is zero; when the SKEW is negative, the data distribution is partial to left, otherwise to right. The definition of SKEW is shown in Equation (3).

$$
S K E W=\frac{n}{(n-1)(n-2)} \sum\left(\frac{x_{i}-A V}{S D}\right)
$$

\subsection{Development of CDC method}

Given the human physiological regulations are affected by environmental and individual factors, a single mathematics metrics, like AV, SD, AD, CV, SKEW, or a parameter combination of some of these metrics, cannot describe the fluctuation characteristics well. As these metrics reflect information for a target variable in multiple dimensions, a multidimensional coordinate system is necessary, to evaluate the regulations of human physiological parameters and identify the differences systematically. Therefore, with the above mentioned AD/ CV/ SKEW as three dimensions in the coordinate system, this study develops a CDC method through introducing the Moment of Inertia (MI) in the Simulated Mass System (MS). Details are introduced in the following section.

\subsubsection{Multidimensional coordinate system}

This method is based on a multidimensional decoupling and reorganizing process, which has been widely used in multi-target assessment $[50,51]$. The method provides quantitative descriptions of the inner-balance, compliance and deviation for a specific system. The CDC method is originally used to analyze the certain changes under the coupled impacts of multiple variables, and provide quantitative evaluation of these factors. A variable $W$ is assumed with a variety of influencing factors fi $(i=1,2,3 \ldots m)$, and shows different variations $V j(j=1,2,3 \ldots n)$. The characteristic feature $C k(k \geq 1)$ is proposed as the corresponding parameter under each $\mathrm{Vj}$ so there is one-to-one relation between the $\mathrm{Cj}$ and $\mathrm{Vj}(\mathrm{k}=1$ in this study). After that, factor $\mathrm{fi}(\mathrm{i}=1,2,3 \ldots \mathrm{m})$ is transferred to a group of characteristic parameters $C_{j}(j=1,2,3 \ldots n)$. The relationship between both forms the subjective mapping through the intermediate function $\mathrm{Vj}$. In this case, each $\mathrm{Cj}$ value represents a combined effect of fi, but this makes it difficult to reflect the comprehensive effect of $V j(j=1,2,3 \ldots n)$, through a single value of $\mathrm{C}$, or a group values of $\mathrm{Ci}$. Therefore, a multidimensional coordinate system is adopted using $\mathrm{Vj}(\mathrm{j}=1,2,3 \ldots \mathrm{n})$ as variable in each dimension, to describe the factor $\mathrm{fi}$ and the effect on W. 


\subsubsection{Simulated Mass System(MS)}

In the coordinate system, the $W$ is reflected by the characteristic parameter $C j(j=1,2,3 \ldots n, k=$ $1)$, using the specific locations $(C 1, C 2, C 3 \ldots C n)$. When studying the single impact of factor $f m$, the other factors of $1,2,3 \ldots \mathrm{m}-1$, are fixed. That is, the $\mathrm{Cj}$ responding to other factors in the range of 1 to $\mathrm{m}-1$ is averaged. Then the unique $\mathrm{Cmj}(\mathrm{j}=1-\mathrm{n})$ can be obtained and a fixed value $\mathrm{Wm}$ under factor $\mathrm{fm}$ is drawn. In summary, the MS is built with the specific values of W1, W2, W3 ...Wm and their corresponding coordinate positions at $\mathrm{Cm} 1, \mathrm{Cm} 2 \ldots \mathrm{Cmj}$... Cmn. The mass distribution, location and size of MSm are all under the control of factor $\mathrm{fm}$, to reflect the effect of $\mathrm{fm}$ on $\mathrm{W}$. The remaining MS1, MS2, MS3... MSm-1 can be obtained from the individual influence of each variable. In addition, when comparing the impact of different fi on $W 1, W 2, W 3 \ldots W m$, to avoid the influence caused by the uncertainty of the number " $\mathrm{m}$ ", normalization process is carried out among W1, W2, W3 ...Wm to build the final Simulated Mass System.

\subsubsection{Moment of Inertia(MI)}

The origin in the coordinate system means that the variable shows absolute stabilization in the coordinate system with the AD, CV and SKEW at value of 0 . A distance from the origin, or a greater abstractive mass point indicates a remarkable fluctuation. The MI is then introduced to describe the deviation between MS and the origin, which demonstrates the comprehensive volatility of each parameter. The $\mathrm{Ml}$, as a concept from the physical point of view, can express both the quality and distance deviation of a particle, a rigid object or a mass system responding to a fixed point in twodimensional space, or a fixed shaft in three-dimensional space. The values are only determined by the size and position. The MI has been used in various areas of scientific experiments, engineering, aerospace, biological research and other industrial and social practices $[48,49]$. The definition of $\mathrm{MI}$ is shown in Equation (4).

$$
\mathrm{MI}=\sum_{\mathrm{i}}^{\mathrm{n}} \mathrm{MR} \mathrm{R}^{2}
$$

Where $M$ represents the mass; $R^{2}$ represents the distance to certain shaft or point.

The Mli of a specific particle in mass system MSc is then achieved in Equation (5).

$$
\operatorname{MIi}=(\mathrm{Wi}) \times\left[\sum \mathrm{Cj}(\mathrm{j}=1,2,3 \ldots n)\right]^{2}
$$

In order to ensure comparability between different individuals, taking the individual Wi divided by $\mathrm{AV}(\mathrm{Wi})$ as each mass point, the two parts of $\mathrm{Mli}$, i.e., $\mathrm{M}$ and $\mathrm{R}^{2}$ are expressed using dimensionless DML (Mi)(Equation (6)) and DML ( $\left.\mathrm{R}^{2}\right)$ (Equation(7)).

$$
\begin{gathered}
\operatorname{DML}(M i)=\frac{m \times w_{i}}{\sum_{i=1}^{m}\left(w_{i}\right)} \\
\operatorname{DML}\left(R^{2}\right)=\sum\left[\operatorname{Nor}\left(C_{j}(j=1,2,3 \ldots n)\right)\right]^{2}
\end{gathered}
$$

Then the influence of factor fi on $\mathrm{Ml}$ is expressed in Equation (8).

$$
M I_{f i}=\sum_{i=1}^{m}\left\{\frac{m \times w_{i}}{\sum_{i=1}^{m}\left(w_{i}\right)} \times \sum[\operatorname{Nor}(C j(j=1,2,3 \ldots n))]^{2}\right\}
$$

From Equations (6)(7), the average maximum values of DLM (Mli)and DLM $\left(R^{2}\right)$ are 1 and $n$ respectively. Therefore, the theoretical range of $\mathrm{Ml}_{\mathrm{fi}}$ is from 0 to $\mathrm{n}$. Then the CDC method can be defined by dividing $\mathrm{Ml}_{\mathrm{fi}}$ by the dimension number " $\mathrm{n}$ ", as shown in Equation (9). 


$$
\mathrm{CDC}=\frac{\Delta}{\mathrm{n}}=\frac{1}{\mathrm{n}} \sum_{i=1}^{m}\left\{\frac{\mathrm{m} \times \mathrm{W}_{\mathrm{i}}}{\sum_{i=1}^{m}\left(\mathrm{~W}_{\mathrm{i}}\right)} \times \sum[\operatorname{Nor}(\mathrm{Cj}(j=1,2,3 \ldots \mathrm{n}))]^{2}\right\}
$$

The calculation process of the CDC values is demonstrated in Figure 1. In this study, three typical physiological parameters of Tre, Tsk and HR of 10 subjects are adopted. Changes of these parameters under nine experimental conditions are analyzed, by calculating AD/ CV/ SKEW in three dimensions. Under such cases, $k=1, n=q=3, p=9, m=10$. The $f(i n)$ represents the individual difference factors and $f(o u t)$ represents the environmental factors. The $W$ reflects the fluctuation characteristics of Tre, Tsk and HR with the influence of individual and environmental factors. Finally, the $C D C$ values for different physiological parameters can be calculated.

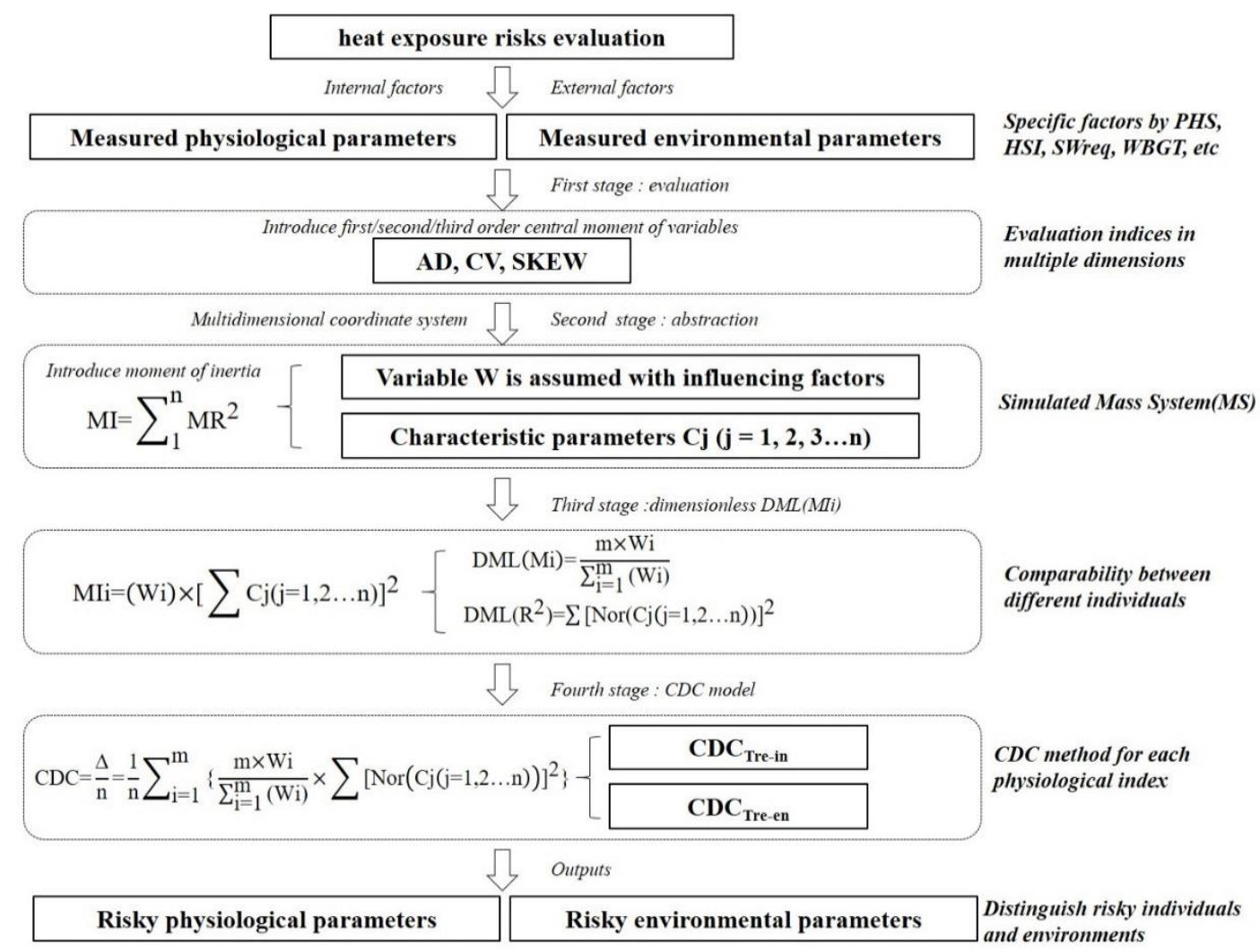

Figure 1 Calculation flow chart for CDC method

Here, taking the physiological parameter of Tre as an example, the mass system of MS(in) for Tre can be built according to Figure 1, and the CDC method to evaluate the individual differences for Tre, namely $C D C_{\text {Tre in }}$ can be expressed in Equation (10).

$$
\mathrm{CDC}_{\operatorname{Tre}_{\mathrm{in}}}=\frac{1}{\mathrm{n}} \sum_{\mathrm{i}=1}^{\mathrm{m}}\left\{\frac{\mathrm{m} \times \operatorname{Tre}_{\mathrm{in}, \mathrm{i}}}{\sum_{\mathrm{i}=1}^{\mathrm{m}}\left(\operatorname{Tre}_{\mathrm{in}, \mathrm{i}}\right)} \times\left[\operatorname{Nor}\left(\mathrm{AD}_{\operatorname{Tre}_{\mathrm{in}, \mathrm{i}}}\right)^{2}+\operatorname{Nor}\left(\mathrm{CV}_{\operatorname{Tre}_{\mathrm{in}, \mathrm{i}}}\right)^{2}+\operatorname{Nor}\left(\mathrm{SKEW}_{\operatorname{Tre}_{\mathrm{in}, \mathrm{i}}}\right)^{2}\right]\right\}
$$

Meantime, the physiological response differences of Tre caused by environmental factors can be evaluated and the $\mathrm{CDC}_{\text {Tre en }}$ is defined in Equation (11)

$$
\mathrm{CDC}_{\operatorname{Tre}}=\frac{1}{\mathrm{n}} \sum_{\mathrm{i}=1}^{\mathrm{m}}\left\{\frac{\mathrm{m} \times \operatorname{Tre}_{\mathrm{en}, \mathrm{i}}}{\sum_{\mathrm{i}=1}^{\mathrm{m}}\left(\operatorname{Tre}_{\mathrm{en}, \mathrm{i}}\right)} \times\left[\operatorname{Nor}\left(\mathrm{AD}_{\operatorname{Tre}_{\mathrm{en}, \mathrm{i}}}\right)^{2}+\operatorname{Nor}\left(\mathrm{CV}_{\operatorname{Tre}_{\mathrm{en}, \mathrm{i}}}\right)^{2}+\operatorname{Nor}\left(\operatorname{SKEW}_{\operatorname{Tre}_{\mathrm{en}, \mathrm{i}}}\right)^{2}\right]\right\}
$$

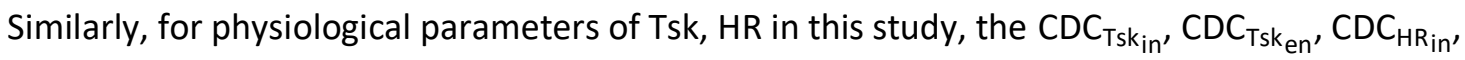
$\mathrm{CDC}_{\mathrm{HR}}$ en can also be defined through replacing the corresponding parameters in Equations (10)(11). 
Taken together, Section 2.2 adopts three typical physiological indices, i.e. Tre, Tsk, HR, and elaborates the calculation process in a multidimensional system. Based on these multidimensional parameters, the CDC method for each physiological index is built and the values can be judged and compared responding to environmental and individual factors.

\section{Data collection}

To verify the proposed $C D C$ method, a heat exposure experiment was conducted in a simulated climate chamber. We collected data from 10 Chinese labor workers, who were exposed to hot environments, with combinations of three temperature levels and three relative humidity levels (nine conditions). The details for experimental designs have been described in Ref. [52].

\subsection{Experimental conditions}

The experimental design was referred to Ref. [53, 54], regarding environmental parameters, activity level, resting time and measuring intervals. Totally 9 typical conditions were designed, as shown in Table 1. Table 1 meantime shows the measured parameters during experiments. The measured temperature and $\mathrm{RH}$ values in Table 1 were close to the designed conditions, suggesting the thermal environments in climate chamber met the experimental demands. Besides, due to the inner enclosure structure in the climate chamber, the measured black-bulb temperatures were close to the dry-bulb temperatures in the chambers, the differences between both being less than $0.5^{\circ} \mathrm{C}$. In the following study, the radiant temperature was thus hypothesized being equal to air temperature.

Table 1 Condition designs and measured parameters in experiments

\begin{tabular}{ccccc}
\hline Conditions & $\begin{array}{c}\text { Designs } \\
(\mathrm{T} / \mathrm{RH})\end{array}$ & $\begin{array}{c}\text { Measured dry-bulb } \\
\text { temperature }\left({ }^{\circ} \mathrm{C}\right)\end{array}$ & $\begin{array}{c}\text { Measured black-bulb } \\
\text { temperature }\left({ }^{\circ} \mathrm{C}\right)\end{array}$ & $\begin{array}{c}\mathrm{RH} \\
(\%)\end{array}$ \\
\hline $\mathrm{C} 1$ & $35^{\circ} \mathrm{C} / 25 \%$ & $35.1 \pm 0.2$ & $34.5 \pm 0.2$ & $25.9 \pm 3.1$ \\
$\mathrm{C} 2$ & $35^{\circ} \mathrm{C} / 40 \%$ & $34.8 \pm 0.3$ & $34.4 \pm 0.3$ & $41.1 \pm 2.2$ \\
$\mathrm{C} 3$ & $35^{\circ} \mathrm{C} / 60 \%$ & $35.0 \pm 0.2$ & $34.6 \pm 0.2$ & $58.9 \pm 3.6$ \\
$\mathrm{C} 4$ & $38^{\circ} \mathrm{C} / 25 \%$ & $37.7 \pm 0.1$ & $37.5 \pm 0.2$ & $25.4 \pm 2.7$ \\
$\mathrm{C} 5$ & $38^{\circ} \mathrm{C} / 40 \%$ & $37.8 \pm 0.2$ & $37.4 \pm 0.3$ & $39.6 \pm 2.3$ \\
$\mathrm{C} 6$ & $38^{\circ} \mathrm{C} / 60 \%$ & $38.3 \pm 0.2$ & $37.6 \pm 0.2$ & $59.1 \pm 1.7$ \\
$\mathrm{C} 7$ & $40^{\circ} \mathrm{C} / 25 \%$ & $39.9 \pm 0.2$ & $39.3 \pm 0.2$ & $25.3 \pm 2.4$ \\
$\mathrm{C} 8$ & $40^{\circ} \mathrm{C} / 40 \%$ & $40.1 \pm 0.1$ & $39.1 \pm 0.3$ & $39.4 \pm 2.8$ \\
$\mathrm{C} 9$ & $40^{\circ} \mathrm{C} / 60 \%$ & $39.9 \pm 0.1$ & $39.3 \pm 0.2$ & $57.9 \pm 2.9$ \\
\hline
\end{tabular}

\subsection{Subjects selection}

Considering the labor workers were one of the populations who may be in high risk to heat exposure, a group of 25 healthy male candidates were randomly selected from a local construction industry in Chongqing. Then they were asked to participate in a pre-experiment of walking on the treadmill at $0.5 \mathrm{~m} / \mathrm{s}$ for $60 \mathrm{~min}$ under $38^{\circ} \mathrm{C} / 40 \%$. Their Tre, Tsk and HR were continuously measured during exposures. After tests, candidates whose Tre, Tsk and HR exceeded the mean \pm 3 SD were excluded[55], to minimize the individual differences. The screening principles and standards for subjects were elaborated in Ref. [52] and finally 10 subjects were selected for the formal experiments. Their basic information is shown in Table 2. Subjects were required to be in accordance with normal resting habits and ensure good sleep 24 hours before tests; no heavy physical work, or drink were allowed. 
Table 2 Basic information for the 10 selected subjects

\begin{tabular}{ccc}
\hline Items & Mean \pm SD & Range \\
\hline Age & $39.4 \pm 3.6$ & $35-48$ \\
Height $/ \mathrm{m}$ & $168 \pm 2.3$ & $164-173$ \\
Weight $/ \mathrm{kg}$ & $59.8 \pm 2.3$ & $55.4-65.6$ \\
BMI index $/ \mathrm{kg} \cdot \mathrm{m}^{-2}$ & $21.2 \pm 0.7$ & $20.1-22.5$ \\
Resting HR/bpm & $68.3 \pm 5.7$ & $59-76$ \\
\hline
\end{tabular}

\subsection{Experiment procedure}

The experiment was performed in accordance with the 1964 Helsinki declaration and its later amendments and comparable ethical standards [58]. Participants were allowed to terminate the tests at any time if they felt uncomfortable during experiments. In addition, according to the recommendations by WHO[59], when a subject's HR exceeded 180bpm for more than $3 \mathrm{~min}$, or Tre was higher than $39^{\circ} \mathrm{C}$ under continuous monitoring, the test was terminated.

Subjects were asked to arrive at the preparation room 30min in advance and change the uniform experimental clothes (T-shirt, shorts, shoes and socks). Then they were asked to attach the thermocouples (TMCX-HD, accuracy: $\pm 0.2^{\circ} \mathrm{C}$ ) on local four body parts (i.e. chest, left upper arm, left thigh, left calf). Data of local skin temperatures were continuously recorded every 10 s and the mean skin temperature for each subject was calculated by the area-weighed four-point method [56]. The rectal temperature was measured by putting sterilized thermocouple probe into subject's rectum at a depth of $10 \mathrm{~cm}$ above the anal sphincter, according to the standard method in ISO 9886 [57]. A heart rate sensor (Polar RS800, Finland, accuracy: $\pm 1 \mathrm{bpm}$ ) was placed at the left of chest with skin contact, to monitor subjects' heart rate, in the time interval of $1 \mathrm{~min}$. After preparations, they were sedentary for $30 \mathrm{~min}$ in the preparation room to eliminate the effects of outdoor environments and metabolic rates. Note that during this period subjects whose measured Tre were higher than $37.4{ }^{\circ} \mathrm{C}$ were excluded for attending tests.

The formal experiment commenced when subjects entered the chamber. Then they were asked to walk on the treadmill at a speed of $0.5 \mathrm{~m} / \mathrm{s}$ at a $10 \%$ grade. According to the guideline of ISO 8996 [60], the estimated metabolic rate was $\sim 160 \mathrm{~W} / \mathrm{m}^{2}$. The test lasted $120 \mathrm{~min}$ and Tre, Tsk and HR of subjects were monitored and recorded continuously. They were free to drink water but the amount was recorded to correct the sweat produced during heat exposure. The instruments and onsite test are shown in Figure 2.

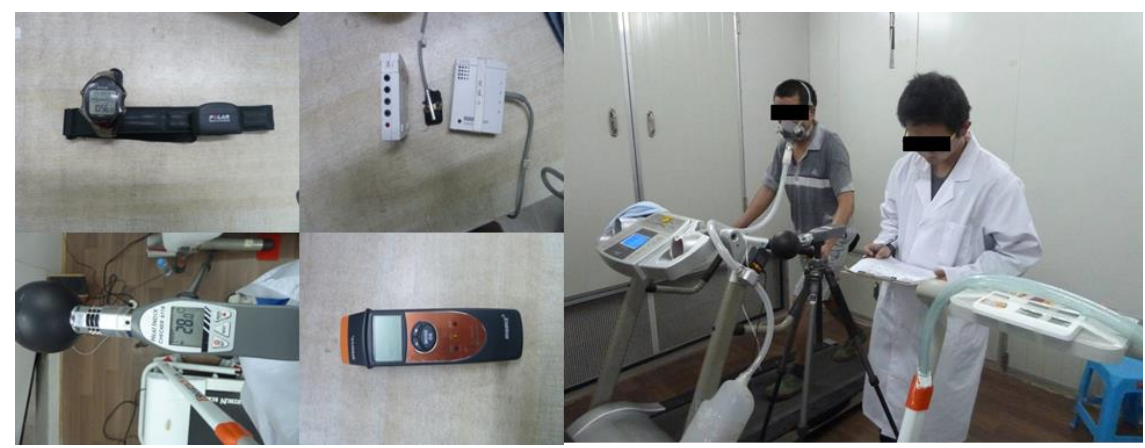

Figure 2 Instruments and onsite experiment in climate chamber 


\section{Results}

Experimental termination was conducted seriously based on the aforementioned situations. To sum up, subjects exhibited different heat tolerance abilities under the same heat exposure condition. Totally $64.7 \%$ of the 90 cases were finished ( 55 out of 90 ) in $120 \mathrm{~min}$ exposure; for the remaining conditions, subjects terminated at different stages within the time length of $120 \mathrm{~min}$. About $85.7 \%$ (30 out of 35 ) terminated the test when their rectal temperature exceeded the threshold.

The mean values of Tre, Tsk and HR of each subject in the whole test ( $\leqslant 120 \mathrm{~min}$ ) were averaged. The indices of AD, CV and SKEW of the 10 subjects for the mean Tre, Tsk and HR values were calculated. The following analyzed the comprehensive controllability of these physiological indices and compared the differences among 1010 subjects) and for the 9 experimental conditions in Section 4.1. The heat risk was evaluated in Section 4.2 through calculating the CDC values for Tre, Tsk and HR.

\subsection{Evaluaiton of subjects' physiological responses}

\subsubsection{Tre variation}

Figure 3 shows the comprehensive changes of Tre of 10 subjects in the 9 conditions (see Table 1), which are displayed in AD, CV , and SKEW. From Figure 3, the values of AD and CV of subjects' Tre increased with temperature under the same RH level. The volatility of Tre also increased with increasing $\mathrm{RH}$ under each temperature level. That is, the $\mathrm{AD}$ and $\mathrm{CV}$ increased gradually with $\mathrm{RH}$ from $25 \%$ to $40 \%$, and to $60 \%$. In addition, there were obvious coupling effect of temperature and $\mathrm{RH}$ under $35^{\circ} \mathrm{C} / 38^{\circ} \mathrm{C} / 40^{\circ} \mathrm{C}$, where the $\mathrm{RH}$ was high (60\%). This indicated that the Tre of subjects was significantly affected by high temperature, especially coupled with high relative humidity.

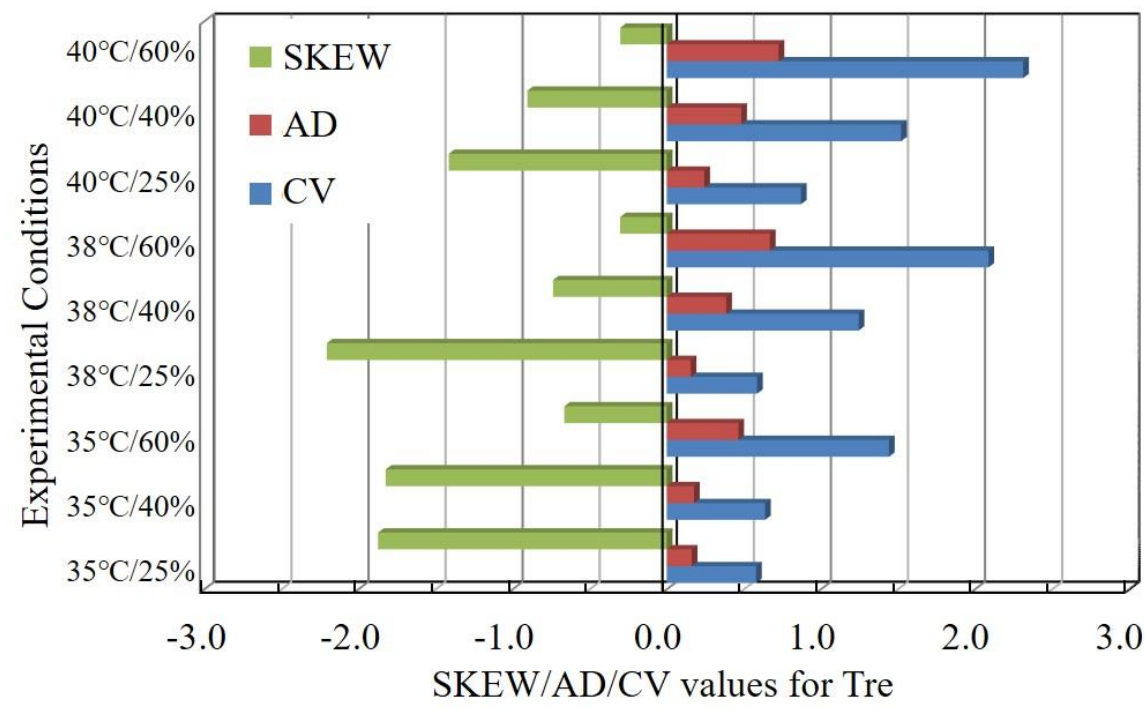

Figure $3 \mathrm{AD}, \mathrm{CV}$ and SKEW values of Tre in 9 conditions 
The SKEW of Tre indeed reflects the curvature and the second derivative in its change trend. In Figure 3, compared to $A D$ and $C V$, a larger SKEW was found at $\mathrm{RH}=25 \%$, and decreased conversely with increasing temperature and $\mathrm{RH}$, indicating an increased control of body to retain the increase of rectal temperature caused by heat stimulus. In particular, the SKEW values were relatively much smaller under conditions of $35^{\circ} \mathrm{C} / 60 \%, 38^{\circ} \mathrm{C} / 60 \%, 40^{\circ} \mathrm{C} / 60 \%$. The SKEW was close to zero, comparing -0.30 at $40^{\circ} \mathrm{C} / 60 \%$ to -0.67 at $35^{\circ} \mathrm{C} / 60 \%$. Overall, the values of SKEW were negative in all 9 conditions, indicating the body physiological regulation for Tre was gradually restrained. The control degree was enhanced with increased temperature and humidity, manifesting a determinant protection for body internal heat balance.

\subsubsection{Tsk variation}

Figure 4 shows the results of the AD/CV/SKEW variations of Tsk of 10 subjects, which shares a similar trend to Tre in Figure 3. According to experimental results, the measured mean Tsk of subjects fluctuated in a narrow range of $34.4-36.8^{\circ} \mathrm{C}$, regardless of a wide temperature range from $35^{\circ} \mathrm{C}$ to $40^{\circ} \mathrm{C}$. As a result, the $A D$ and $\mathrm{CV}$ values of Tsk were small. Moreover, the SKEW distributions of Tsk and Tre were similar to each other but the average value of SKEW for Tsk in 9 conditions was bigger than that for Tre (1.51>1.14). This was inferred that the heat transfer on skin surface by convection and evaporation was more significant compared to the heat exchange in inner body, leading to stronger regulation response on Tsk to alleviate heat strain.

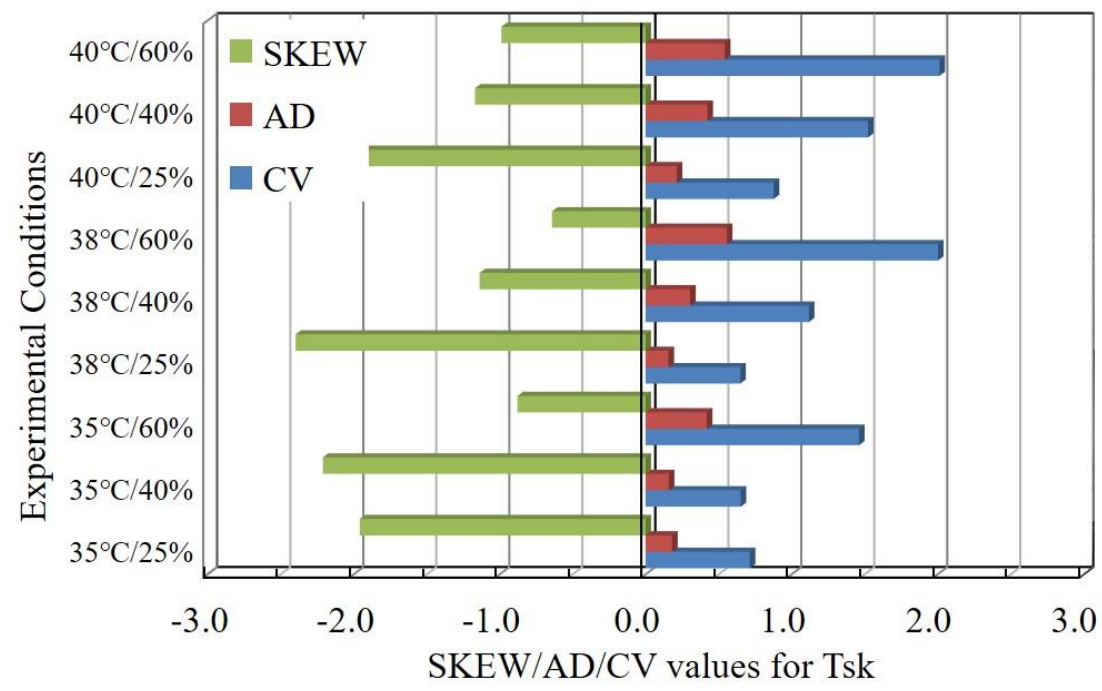

Figure $4 \mathrm{AD}, \mathrm{CV}$ and SKEW values of Tsk in 9 conditions

Further comparing the changes of SKEW of Tre and Tsk, the mean values of SKEW of Tre decreased by 0.21 between $38^{\circ} \mathrm{C}-25 \% / 40 \% / 60 \%$ and $40^{\circ} \mathrm{C}-25 \% / 40 \% / 60 \%$; while the SKEW for Tsk was less affected by environmental temperature and $\mathrm{RH}$ and the value was only 0.08 . Besides, the increased RH had negative effects on SKEW(Tsk), comparing $25 \%$ to $60 \%$ respectively. This was attributed to that the higher $\mathrm{RH}$ inhibited the body sweat regulation and evaporative heat loss, especially when the air temperature was higher than the skin temperature. An interesting finding was that the maximum SKEW for both Tre and Tsk occurred at $38^{\circ} \mathrm{C} / 25 \%$ rather than under high temperature and humidity conditions. We inferred that the $38^{\circ} \mathrm{C} / 25 \%$ condition provided a stronger heat stimulus on body compared to $35^{\circ} \mathrm{C}-25 \% / 40 \% / 60 \%$, which enhanced the convective heat transfer between skin surface and ambient environment. On the other hand, compared to much stronger heat stimulus, the water vapor pressure differences between skin surface and surroundings was bigger at $38^{\circ} \mathrm{C} / 25 \%$, leading to stronger sweating regulation in body. 
4.1.3 HR variation



Figure $5 \mathrm{AD}, \mathrm{CV}$ and SKEW distribution of HR in 9 conditions

Figure 5 shows the changes of SKEW/AD/CV, demonstrating a comprehensive controllability of HR of subjects. In general, the AD, CV and SKEW of HR fluctuated among different conditions but did not show significant increasing/decreasing trends with temperature and $\mathrm{RH}$, compared to the Tre and Tsk. This was reflected by the small ratios of max/min of AD and CV, about 1.70 and 1.57 respectively; while the values were 4.68 and 3.99 for Tre, and 3.54 and 3.10 for Tsk. The SKEW variation of HR showed an opposite change compared to Tre and Tsk: when the temperature and $\mathrm{RH}$ gradually increased, the values of SKEW increased. This indicated that the human body presented effective controls on body heart rates, to respond to temperature and humidity increasing.

\subsection{Comparisons between external and internal effects}

Figures 3-5 shows the Tre, Tsk and HR variations of subjects in response to environmental temperature and $\mathrm{RH}$, from a multidimensional point of view. Our initial assumption was: when there were no individual differences among 10 subjects, theoretically there would be no differences for Tre, Tsk, and HR regulations after they were exposure to the same heat stimuli. Figure 6 shows the actual values of AD/CV/SKEW of Tre/Tsk/HR among the 10 subjects. The 10 kinds of colors in Figure 6 represent the 10 subjects; the 9 inside-to-outside rings represent 9 indices among 10 subjects, i.e. $A D(T r e), A D(T s k), A D(H R)$, SKEW(Tre), SKEW(Tsk), SKEW(HR), CV(Tre), CV(Tsk) and CV(HR), according to Equations (1-3). In theory, for each metric, the proportion of $A D / C V / S K E W$ among the 10 subjects should be distributed evenly, namely $10 \%$ for each ring in Figure 6 . However, there were significant variations of subjects' physiological regulations. For SKEW, the negative values suggested the skew was left and the median for measured Tre, Tsk and HR were distributed on the right of means, which was consistent with Figures 3-5. The absolute values of AD/CV/SKEW of Tre/Tsk/HR among the 10 subjects varied between $7 \%$ and $14 \%$, rather than being equal to $10 \%$. In fact, despite the strict control in experiments for age, gender, weight, height and fat ratio [28] of subjects, some unpredictable factors still existed, resulting in the different thermal responses to heat stimuli. However, in most studies for heat stress, the average values are usually adopted and such individual differences are largely simplified or neglected, which lead to a deviation when predicating health risks for personal individual[31, 32]. 


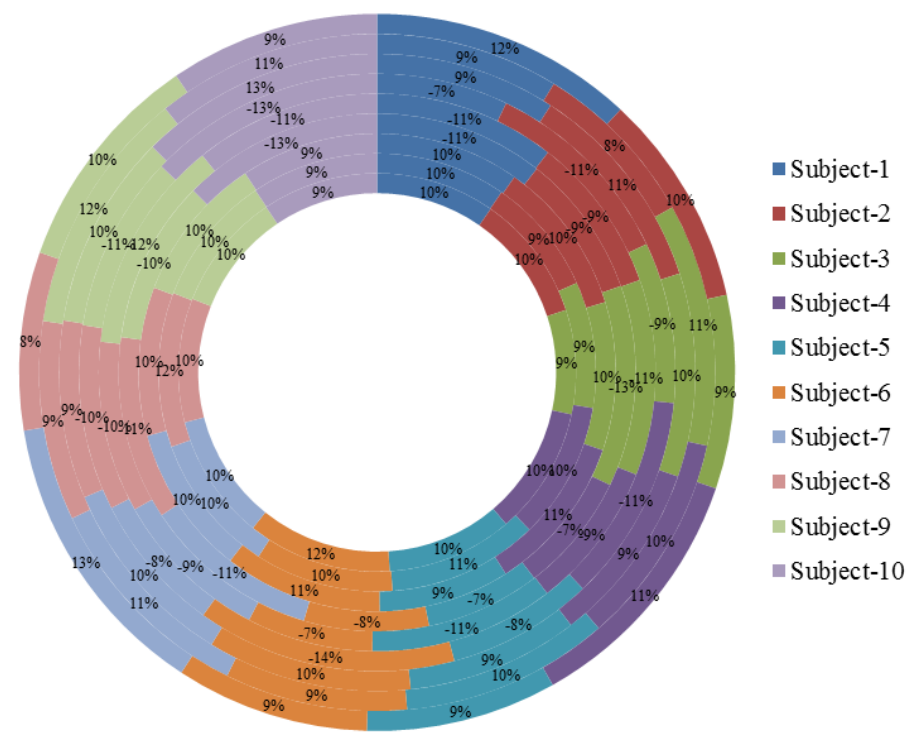

Figure 6 Distribution of AD/ SKEW/CV of Tre/Tsk/HR among 10 subjects

Figure 6 provides an intuitive description of physiological differences among 10 subjects. To evaluate the integrated impacts of both individual factors and environmental factors, we recalculated the CV values of AD/CV/SKEW variations for Tre/Tsk/HR, expressed as CV[AD(Tre/Tsk/HR), CV (Tre/Tsk/HR), SKEW (Tre/Tsk/HR)] and made a comparison between environment and individual, as shown in Figure 7. From Figure 7, whatever the dimensions were, the values of $\mathrm{CV}$-environment were greater than that of $\mathrm{CV}$-individual, revealing the dominant role of environmental factors on human heat strain during heat exposure. In addition, the HR showed the smallest variability in CV[AD/CV/SKEW], which was followed by Tsk. While the values of $\mathrm{CV}[\mathrm{AD} / \mathrm{CV} / \mathrm{SKEW}]$ for Tre were the biggest, showing the largest variability of human rectal temperatures influenced by both individual and environmental factors.

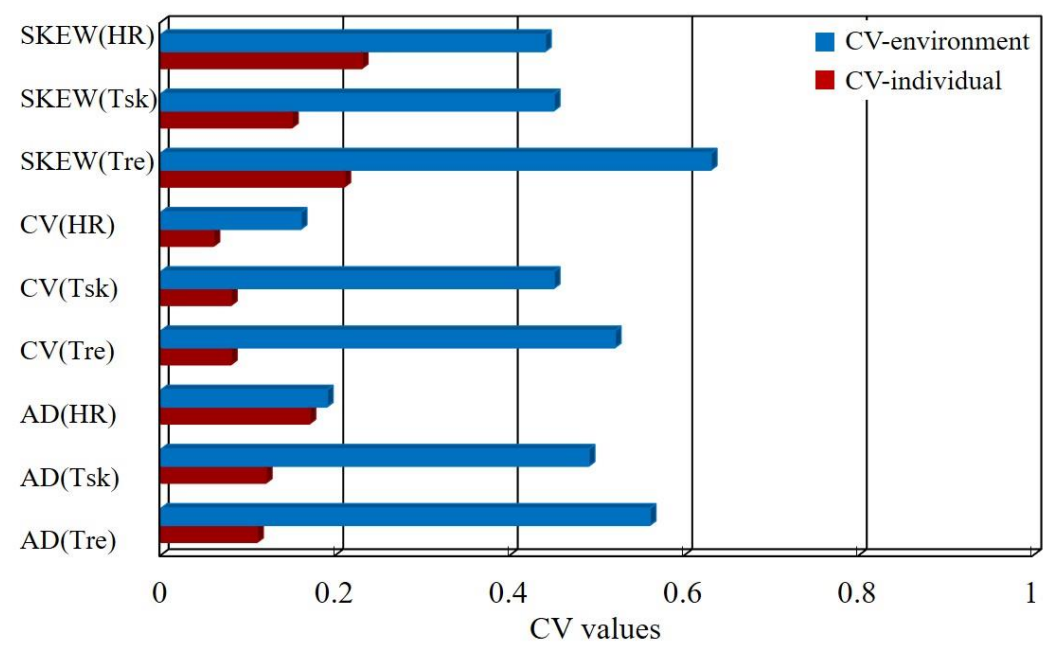

Figure $7 \mathrm{CV}[\mathrm{AD} / \mathrm{CV} / \mathrm{SKEW}$ (Tre/Tsk/HR)] with individual and environmental factors 


\subsection{Evaluation for CDC values}

Based on the method presented in Section 2.2, the CDC values for Tre/Tsk/HR under 9 experimental conditions and within 10 subjects were calculated. The values indeed reflected the variation degrees of human physiological indices responding to environmental stimuli and individual differences: the bigger the values were, the stronger physiological responses the body had, the higher risk for heat strain there would be.

\subsubsection{CDC differences caused by individual factors}

Given individual differences, the CDC values for 10 subjects are shown in Table 3. Considering the variations of rectal temperature and heart rates were more vital indices for human health and safety, the CDC values for Tre and HR were discussed. From Table 3, the CDC values for subject No. 6 were the highest, $1.14 \%$ for Tre and $1.39 \%$ for HR respectively (bold in Table 3). In contrast, subject No. 5 had the smallest CDC value of $0.88 \%$ for Tre and $0.74 \%$ for HR respectively. Table 5 meantime presents the basic information of the 10 subjects. Compared to subject No.6, subject No. 5 was younger, and had the relatively bigger body surface area, which was beneficial for heat loss at skin surface. As a result, looking the 10 subjects as a whole, we could infer that subject No. 6 was with the higher risk and subject No. 5 was relatively safe when they were exposed to the same hot environments.

Table 3 CDC analysis for the internal differences of the Tre/Tsk/HR among subjects

\begin{tabular}{lllllllll}
\hline Subjects & $\begin{array}{l}\text { Age } \\
/ \mathrm{yr}\end{array}$ & $\begin{array}{l}\text { Height } \\
/ \mathrm{m}\end{array}$ & $\begin{array}{l}\text { Weight } \\
/ \mathrm{kg}\end{array}$ & $\begin{array}{l}\mathrm{Adu} \\
/ \mathrm{m}^{2}\end{array}$ & $\begin{array}{l}\mathrm{HR}_{0} \\
\mathrm{bpm}\end{array}$ & $\begin{array}{l}\mathrm{CDC}_{\text {Tre }} \\
(100 \%)\end{array}$ & $\begin{array}{l}\mathrm{CDC}_{\text {Tsk }} \\
(100 \%)\end{array}$ & $\begin{array}{l}\mathrm{CDC}_{\mathrm{HR}} \\
(100 \%)\end{array}$ \\
\hline No. 1 & 48 & 1.72 & 67.5 & 1.79 & 57 & 1.00 & 0.97 & 0.84 \\
No. 2 & 43 & 1.65 & 63.2 & 1.69 & 59 & 0.97 & 0.76 & 1.12 \\
No. 3 & 35 & 1.63 & 58.9 & 1.63 & 65 & 0.99 & 1.01 & 0.91 \\
No. 4 & 37 & 1.69 & 58.9 & 1.67 & 69 & 0.92 & 0.96 & 1.13 \\
No. 5 & 37 & 1.75 & 69.2 & 1.83 & 71 & 0.88 & 1.21 & 0.74 \\
No. 6 & 42 & 1.69 & 59.7 & 1.68 & 65 & 1.14 & $\mathbf{0 . 9 1}$ & 1.39 \\
No. 7 & 41 & 1.63 & 59.4 & 1.63 & 68 & 1.10 & 1.00 & 0.93 \\
No. 8 & 45 & 1.71 & 57.7 & 1.67 & 69 & 1.11 & 1.22 & 1.04 \\
No. 9 & 38 & 1.61 & 56.9 & 1.59 & 76 & 0.95 & 1.11 & 0.94 \\
No. 10 & 39 & 1.7 & 59.7 & 1.69 & 73 & 1.11 & 0.97 & 1.14 \\
\hline
\end{tabular}

To make the comparisons much clearer, Figure 8 demonstrates the distributions of $C D C$ values for Tre/Tsk/HR among the 10 subjects, using the data in Table 3 of the last three columns. As expected, subject No. 5 showed smaller CDC values for Tre and HR, indicating the lower heat strain in inner body, meanwhile the higher CDC value for Tsk indicated a stronger ability of heat loss from skin surface. From this point of view, subject No. 6 was vulnerable to hot exposure, who had higher CDC values for Tre and HR. This indicated that subject No. 6 had a higher risk for physiological strain and should be protected to reduce the potential heat-related accidents. 


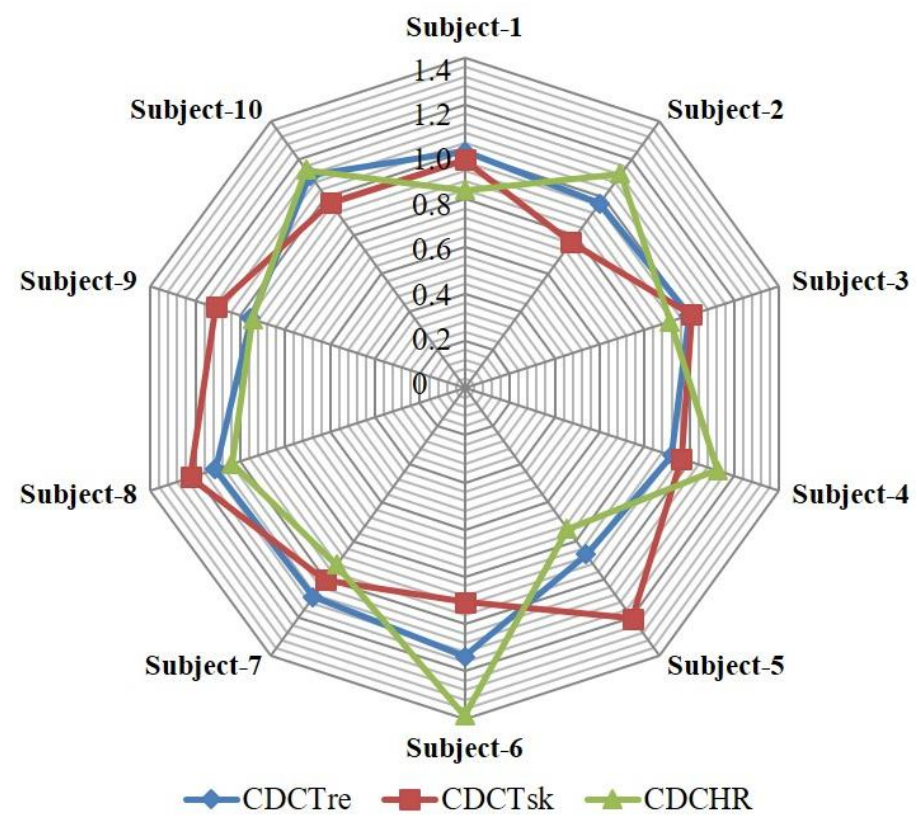

Figure 8 Individual CDC volatility among the 10 subjects

\subsection{2 $\mathrm{CDC}$ differences caused by environmental factors}

In a similar vein, Table 4 shows the fluctuations of physiological indices caused by various temperature and RH. From Table 4, the CDC values of Tre, Tsk, and HR were higher under $60 \%$ at each temperature level, and reached the peak values of $2.69 \%, 2.37 \%, 2.38 \%$ respectively at $40^{\circ} \mathrm{C} / 60 \%$. This indicated that the thermal environment of $40^{\circ} \mathrm{C} / 60 \%$ would cause the strongest physiological strain on human body, meaning it was riskier at such condition, compared to other conditions.

Table 4 The CDC analysis on the impact of environment on Tre, Tsk and HR

\begin{tabular}{lllll}
\hline Conditions & $\mathrm{T}\left({ }^{\circ} \mathrm{C}\right) / \mathrm{RH}(\%)$ & $\mathrm{CDC}_{\text {Tre }}(100 \%)$ & $\mathrm{CDC}_{\mathrm{Tsk}}(100 \%)$ & $\mathrm{CDC}_{\mathrm{HR}}(100 \%)$ \\
\hline $\mathrm{C} 1$ & $35^{\circ} \mathrm{C} / 25 \%$ & 1.27 & 0.95 & 0.94 \\
$\mathrm{C} 2$ & $35^{\circ} \mathrm{C} / 40 \%$ & 1.25 & 1.09 & 0.92 \\
$\mathrm{C} 3$ & $35^{\circ} \mathrm{C} / 60 \%$ & 1.34 & 1.39 & 1.18 \\
$\mathrm{C} 4$ & $38^{\circ} \mathrm{C} / 25 \%$ & 1.70 & 1.24 & 0.77 \\
$\mathrm{C} 5$ & $38^{\circ} \mathrm{C} / 40 \%$ & 1.03 & 0.96 & 1.60 \\
$\mathrm{C} 6$ & $38^{\circ} \mathrm{C} / 60 \%$ & 2.29 & 2.22 & 1.28 \\
$\mathrm{C} 7$ & $40^{\circ} \mathrm{C} / 25 \%$ & 1.02 & 1.32 & 1.63 \\
$\mathrm{C} 8$ & $40^{\circ} \mathrm{C} / 40 \%$ & 1.60 & 1.60 & 1.28 \\
$\mathrm{C} 9$ & $40^{\circ} \mathrm{C} / 60 \%$ & 2.69 & 2.37 & $\mathbf{2 . 3 8}$ \\
\hline
\end{tabular}

Figure 9 intuitively exhibits the CDC distributions of subjects' Tre, Tsk and HR under 9 conditions according to Table 4 . The remarkably higher values of $C D C_{\text {Tre }}, C D C_{\text {Tsk, }}, C D C_{H R}$ were found under $40^{\circ} \mathrm{C} / 60 \% \mathrm{RH}$. This would benefit for managers to avoid such environments, or take measurements, like creating urban green-blue spaces to achieve cooling effects in practical working placeError! Reference source not found., to minimize the risks of over-heating for workers. 


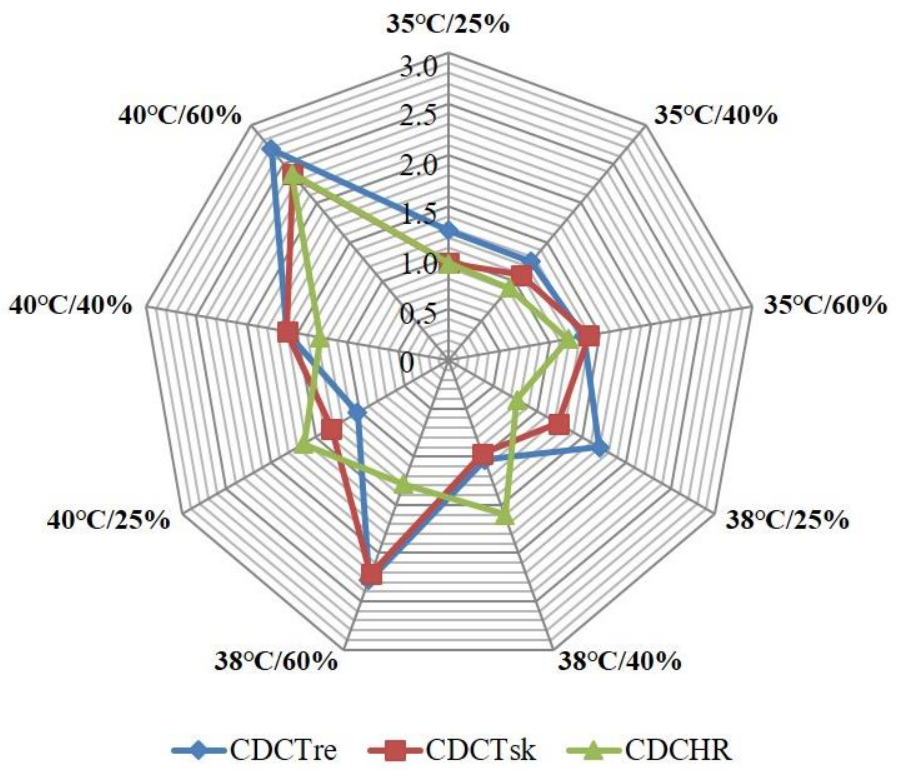

Figure $9 \mathrm{CDC}$ volatility under 9 conditions

\section{Discussions}

Yao et al.Error! Reference source not found. conducted a heat exposure experiment in chamber and found that the mean skin temperature and mean heart rate of subjects increased with increasing environmental temperature and relative humidity. In contrast, the calculated CDC values in Table 4 for Tre, Tsk and HR increased with increasing temperature; while such change trends were not found for increasing relative humidity. This was similar to one study by Du et al Error! Reference source not found.: though the temperature and relative humidity were increased during heat exposure, the number of subjects who were terminated at each condition was not linearly increased and the number of subjects who finished the heat exposure was conversely higher under hot-dry condition $\left(40^{\circ} \mathrm{C} / 25 \%\right)$ than that under slightly hot-humid condition $\left(38^{\circ} \mathrm{C} / 60 \%\right)$. This was attributed to the coupled effects of temperature and relative humidity in hot environment that the human thermal physiological responses caused by humidity stimuli were slight with a certain temperature range. Therefore, in Table 4, the values of $\mathrm{CDC}_{\text {Tre }}$ and $C D C_{\text {Tsk }}$ were slightly smaller at $38^{\circ} \mathrm{C} / 40 \%$ than that at $38^{\circ} \mathrm{C} / 25 \%$. Moreover, the individual differences existed that different subjects responded to different extent when they were exposed to the same thermal stimuli. This could be found in Table 3 and Figure 6 that the regulations of Tre, Tsk and HR differed under different conditions. However, when the environmental temperature and relative humidity were the highest, the effect caused by environmental stimuli was higher that of individual differences. In that case, all the CDC values for Tre, Tsk, and HR were the highest under the condition of $40^{\circ} \mathrm{C} / 60 \%$. 
. This study measured local skin temperatures at four local body parts; considering the skin temperature was not the same in different parts of the bodyError! Reference source not found., and the current models like PHS modelError! Reference source not found., predicted the mean skin temperature from the whole, the area-weighted methodError! Reference source not found. was also adopted for calculating mean skin temperature.

The PHS model is a widely used rational model, but it predicts human heat strain for average people rather than at individual levelError! Reference source not found.. In laboratory experiments, to minimize the individual differences, researchers would screen the subjects strictly, considering ages, gender, weight, height, BMI, etc Error! Reference source not found.Error! Reference source not found.. This study selected subjects through pre-tests and excluded subjects whose physiological indices responded outside the normal range. However, in real working place, due to the complexity, there are so many factors indirectly influencing the physiological response of human body and heat stress or specific strains must adequately account for an individual's personal attributes. These include the location (region and micro-climates)Error! Reference source not found., daily habits, health status, clothes and metabolic ratesError! Reference source not found.Error! Reference source not found., which are unable to be calculated in the CDC method in this study, or quantified algebraically using models. In particular, the thermal history and acclimatization from people would modify the settings of the physiological thermoregulation system themselves, leading to different responses to continuous exposure to heatError! Reference source not found.Error! Reference source not found.. As a result, the uncertainties of individual differences make it difficult for current models for proper application to heat stress predictionError! Reference source not found.Error! Reference source not found.. In this context, the CDC method in the current study provides a comprehensive index to evaluate the heat exposure risk, which enables to identify the high-risk environments and individuals in a quantitative way.

However, the current study providing the CDC method to identify the risk bases on a relative comparison from the point of view of a group of people, or a series of thermal conditions. We assume that the high CDC values are relatively risky and should be paid attentions to. However, the current study is limited to answer which ranges of CDC values for physiological indices are safe and which ranges are in risk during heat exposure. Future work should be developed for the CDC method to determine the baselines: at which CDC limits workers should be protected, to which degree the interventions should be provided. This is expected to provide better grades/levels for risk assessment for heat stress within/without building environment.

\section{Conclusions}


This study induced a three-dimensional indices of Absolute Variation (AD), Coefficient of Variation (CV) and Skewness (SKEW) and evaluated the physiological response differences of rectal temperature (Tre), skin temperature (Tsk) and heart rate (HR) responding to environment and individual, based on a heat exposure experiment. The results showed the AD and CV of subjects' Tre, Tsk and HR increased with temperature and humidity while the SKEW decreased. The interindividual variability was verified, revealing a different body controllability responding to heat stress.

A Comprehensive Deviation Coefficient (CDC) method was developed through introducing Simulated Mass System and Moment of Inertia, and the values of $\mathrm{CDC}_{\mathrm{Tre}}, \mathrm{CDC}_{\mathrm{Tsk}}$ and $\mathrm{CDC}_{\mathrm{HR}}$ responding to different temperature and humidity and among 10 subjects were calculated. The outcomes identified the thermal environment of $40^{\circ} \mathrm{C} / 60 \%$ and the potential vulnerable subject with the most high-risk.

The CDC method enables to quantify the response of physiological indices and compare the inter-individual differences. It can afford a timelier response to examine the high-risk environments and sensitive populations in practical working places. The outcomes are expected to guide hot environment management, identify high-risk populations, make interventions for workers, contributing to minimizing the risks of heat accident occurrences in advance and mitigating the impacts of extreme climates on people's health and safety.

\section{Acknowledgement}

The authors would like to thank the financial support from the National Key R\&D Program of China (Grant No: 2016YFC0700300), the Natural Science Foundation of China (Grant No: NSFC 51561135002), associated with the UK Engineering and Physical Sciences Research Council (EPSRC $\mathrm{EP} / \mathrm{N} 009797 / 1)$.

\section{References}

[1] World Meteorological Organization, WMO Statement on the State of the Global Climate in 2017, World Meteorological Organization, Geneva, Switzerland, 2018.

[2] Met Office, Hot spell June 2017, (2018-01-19)[2019-09-25].

https://www.metoffice.gov.uk/binaries/content/assets/metofficegovuk/pdf/weather/learn-about/ukpast-events/interesting/2017/hot-spell-june-2017---met-office.pdf

[3] K. Weston, BBC Weather: Europe boils in $400 \mathrm{C}$ heatwave as sweltering air engulfs continent, (2019-07-19)[2019-10-05].https://www.express.co.uk/news/weather/1155501/BBC-Weather-forecastEurope-heatwave-France-Portugal-Spain-Met-Office-UK-news-latest-map.

[4] S. Solomon, D. Qin, M. Manning, Z. Chen, M. Marquis, K.B. Averyt, M. Tignor, H.L. Miller, IPCC 2007: Summary for Policymakers, Cambridge University Press, 2007.

[5] J.A. Patz, D. Campbelllendrum, T. Holloway, J.A. Foley, Impact of regional climate change on human health, Nature 408(2005) 310-317.

[6] A. Grundstein, J. Dowd, Trends in Extreme Apparent Temperatures over the United States, 19492010, J Appl Meteorol Climatol 50(2011) 1650-1653.

[7] US Center For Disease Prevention, Heat Stress, 2011.

[8] A.O. Emmanuel, Y. Li, S. Zheng, A. Vaidyanathan, K. Silver, Assessing Heat-Related Mortality Risks among Rural Populations: A Systematic Review and Meta-Analysis of Epidemiological Evidence, Int J Environ Res Public Health 15(2018) 1597-1612. 
[9] M. Liu, S. Gu, P. Bi, J. Yang, Q. Liu, Heat Waves and Morbidity: Current Knowledge and Further Direction-A Comprehensive Literature Review, Int J Environ Res Public Health 12(2015) 5256-5283.

[10] C. Huang, A. Barnett, X. Wang, S. Tong, The impact of temperature on years of life lost in Brisbane, Australia, Nature Climate Change 2(2012) 265-270.

[11] W. Yi, A.P. Chan, Effects of temperature on mortality in Hong Kong: a time series analysis, Int J Biometeorol 59(7)(2015) 927-936.

[12] G.B. Anderson, M.L. Bell, Heat Waves in the United States: Mortality Risk during Heat Waves and Effect Modification by Heat Wave Characteristics in 43 U.S. Communities, Environ Health Perspect 119(2011) 210-218.

[13] K. Knowlton, M. Rotkin-Ellman, G. King, H.G. Margolis, D. Smith, G. Solomon, R. Trent, P. English, The 2006 California Heat Wave: Impacts on Hospitalizations and Emergency Department Visits, Environ Health Perspect 117(2009) 61-67.

[14] A. Gasparrini, Y. Guo, M. Hashizume, et al. Mortality risk attributable to high and low ambient temperature: a multi-country observational study, Lancet 386(2015) 369-375.

[15] World Meteorological Organization(WMO). The global climate 2001-2010, World Meteorological Organization, 2011.

[16] G. Fouillet, F. Laurent, G. Pavillon, S. Bellec, C. Guihenneuc, et al. Excess mortality related to the August 2003 heat wave in France, Int Arch Occup Environ 80(2006) 16-24.

[17] K. Steul, M. Schade, U. Heudorf, Mortality during heatwaves 2003-2015 in Frankfurt-Main - the 2003 heatwave and its implications, Int J Hyg Environ Health. 221(2017) 81-86.

[18] Centers for Disease Control(CDC), Heat illness and deaths-New York City, 2000-2011, Morb Mortal Wkly Rep 62 (2013) 617-621.

[19] C. Huang, J. Cheng, D. Phung, B. Tawatsupa, W. Hu, Z. Xu, Mortality burden attributable to heatwaves in Thailand: A systematic assessment incorporating evidence-based lag structure, Environ Int 121(2018) 41-50.

[20] J. Yang, P. Yin, J. Sun, B. Wang, Q. Liu, Heatwave and mortality in 31 major Chinese cities: Definition, vulnerability and implications, Sci Total Environ 649(2018) 695-702.

[21] L.L. Jackson, H.R. Rosenberg, Preventing heat-related illness among agricultural workers, J Agromedicine 15(2010) 200-215.

[22] R.A.I. Lucas, Y. Epstein, T. Kjellstrom, Excessive occupational heat exposure: a significant ergonomic challenge and health risk for current and future workers, Extreme Physiol Med 3(2014) 1-8.

[23] A.P.C. Chan, W. Yi, D.P. Wong, M.C.H. Yam, and D.W.M. Chan, Determining an optimal recovery time for construction rebar workers after working to exhaustion in a hot and humid environment, Build Environ 58(2012) 163-171.

[24] Health and Safety Executive, Advice for outdoor workers from the heath and safety executive and the health departments in England, Scotland and Wales-keep your top on health risks from working in the sun. 7 Nov, 2014. http://www.hse.gov.uk/pubns/indg147.pdf.

[25] Y. Zhang, D. Shi, R. Guo, et al. Single image modeling (SIM) for predicting the temperature and airflows of outdoor air zones in regional planning. Sustain Cities Soc, 53(2020)101934.

[26] G. Havenith, D. Fiala, Thermal Indices and Thermophysiological Modeling for Heat Stress, Compr Physiol. 6(1)(2016) 255-302.

[27] ISO 7933. Ergonomics of the thermal environment analytical determination an interpretation of heat stress using calculation of the predicted heat strain. International Standards Organization, 2004. 
[28] K.C. Parsons, Human thermal environments: the effects of hot, moderate, and cold environments on human health, comfort, and performance, London, CRC Press, 2014.

[29] P. Roghanchi, K.C. Kocsis, Challenges in Selecting an Appropriate Heat Stress Index to Protect the Workers in Hot and Humid Underground Mines, Safety Health at Work, 2017.

[30] H. Zhang, C. Huizenga, E. Arens, T. Yu, Considering individual physiological differences in a human thermal model, J Therm Biol 26(2001) 401-408.

[31] F. Wang, K. Kuklane, C. Gao, I. Holmér, Can the PHS model (ISO7933) predict reasonable thermophysiological responses while wearing protective clothing in hot environments? Physiol Measurement 32(2011) 239-249.

[32] C. Aubrecht, Ã.Z. D, Identification of heat risk patterns in the U.S. National Capital Region by integrating heat stress and related vulnerability, Environ Int 56(2013) 65-77.

[33] J. Zhao, S. Lorenzo, N. An, W. Feng, L. Lai, S. Cui, Effects of heat and different humidity levels on aerobic and anaerobic exercise performance in athletes, J Exerc Sci Fit 11(1)(2013) 35-41.

[34] X. Shi, N. Zhu, G. Zheng, The combined effect of temperature, relative humidity and work intensity on human strain in hot and humid environments, Build Environ 69(2013) 72-80.

[35] J. Corbett, R.A. Rendell, H.C. Massey, J.T. Costello, M.J. Tipton, Inter-individual variation in the adaptive response to heat acclimation, J Therm Biol 74(2018) 29-36.

[36] K.K. Zander, S.A. Moss, S.T. Garnett, Drivers of self-reported heat stress in the Australian labour force, Environ Res 152(2017) 272-279.

[37] S. Racinais, M. Mohr, M. Buchheit, S.C. Voss, N. Gaoua, J. Grantham, L. Nybo, Individual responses to short-term heat acclimatisation as predictors of football performance in a hot, dry environment, Br J Sports Med 46(2012) 810-815.

[38] S. Racinais, M. Buchheit, J. Bilsborough, P.C. Bourdon, J. Cordy, A.J. Coutts, Physiological and Performance Responses to a Training-Camp in the Heat in Professional Australian Football Players, Int J Sports Physiol Perform 9(4)(2013) 598-603.

[39] W. Yi, A.P.C. Chan, X. Wang, and J. Wang, Development of an early-warning system for site work in hot and humid environments: A case study, Automat Constr 62(2016) 101-113.

[40] A.A.P. Chan, W. Yi, D.W.M. Chan, D.P. Wong, Using the Thermal Work Limit as an Environmental Determinant of Heat Stress for Construction Workers, J Manage Eng 29(2013) 414-423.

[41] A.P.C. Chan, M.C.H. Yam, J.W.Y. Chung, W. Yi, Developing a heat stress model for construction workers, J Fac Manage 10(2012) 59-74.

[42] C.E. Reid, M.S. O'Neill, C.J. Gronlund, S.J. Brines, D.G. Brown, A.V. Diezroux, J. Schwartz, Mapping community determinants of heat vulnerability, Environ Health Perspect 117(2009) 1730-1736.

[43] S.S. Brucelow, D. Cotterrell, G.E. Jones, Heart rate variability during high ambient heat exposure., Aviat Space Environ Med 77(9)(2006)915-920.

[44] P.A. Chapon, N. Bessot, A. Gauthier, F. Kauffman, B. Sesboü Eacute, S. Moussay, Core temperature response to cycling exercise: Effect of time of day and measurement site, J Therm Biol 37(4)(2012) 355-360.

[45] S. Nahmias, Production and Operations Analysis(7th), Waveland Press, Inc, US, 1997.

[46] B.S. Everitt, The Cambridge dictionary of statistics, Cambridge University Press, UK, 2010.

[47] G.F. Reed, F. Lynn, B.D. Meade, Use of coefficient of variation in assessing variability of quantitative assays, Clin Diagn Lab Immunol 9(2002) 1235-1239. 
[48] B. Majumder, K. Yagi, N. Yunes, Improved Universality in the Neutron Star Three-Hair Relations, Phys Rev D. 92(2)(2015) DOI:https://doi.org/10.1103/PhysRevD.92.024020.

[49] N.C. Jr, F.B. Ribeiro, The spin-orbit resonant problem including core mantle gravitational coupling, Comput Appl Math 34(2)(2015) 1-13.

[50] Y. Li, W. Yu, B. Li, R. Yao, A multidimensional model for green building assessment: A case study of a highest-rated project in Chongqing, Energ Build 125(2016) 231-243.

[51] X.H. Wu, P.P. Liu, G.H. Fu, Research on green building standards system based on OPT dimension. Const Economy. 10(2013) 16-20. (In Chinese).

[52] C. Du, B. Li, Y. Li, M. Xu, R. Yao, Modification of the Predicted Heat Strain (PHS) model in predicting human thermal responses for Chinese workers in hot environments, Build Environ 165(2019):106349.

[53] K.C. Parsons, Human heat stress, CRC Press, London, 2019.

[54] L. S, Research on Human Heat Tolerance under Extreme Heat Environment (In Chinese), Tianjin University, Tianjin, 2007.

[55] E. Ziegel, Understanding Statistical Process Control, Technometrics 35(1)(1995)101-102.

[56] N.L. Ramanathan, A new weighting system for mean surface temperature of the human body, J Appl Physiol 19(19)(1964)531-533.

[57] ISO 9886 Ergonomics-evaluation of thermal strain by physiological measurements, International Standards Organization, 2004.

[58] World Medical Association(WMA). WMA Declaration of Helsinki - Ethical Principles for Medical Research Involving Human Subjects, in 64th WMA General Assembly, Fortaleza, Brazil, October 2013.

[59] D. Turner, Health Factors Involved in Working under Conditions of Heat Stress, Br J Ind Med 26(1969) 346.

[60] ISO 8996. Ergonomics of the thermal environment: determination of metabolic rate. International Standards Organization, 2004.

[61] D. Shi, J. Song, J. Huang, et al. Synergistic cooling effects (SCEs) of urban green-blue spaces on local thermal environment: A case study in Chongqing, China. Sustain Cities Soc, 55(2020)102065.

[62] R. Yao, Y. Li, C. Du, B. Li, A 'heart rate'-based model (PHSHR) for predicting personal heat stress in dynamic working environments. Build Environ 135(2019):318-329.

[63] A. Psikuta, R. Niedermann and R.M. Rossi, Effect of ambient temperature and attachment method on surface temperature measurements, Int J Biometeorol 58(5)(2014) 877-885.

[64] D. Enescu, A review of thermal comfort models and indicators for indoor environments, Renew Sust Energ Rev 79(2017):1353-1379.

[65] T. Chaudhuri, D. Zhai, Y. C. Soh, H. Li, Li. Xie, Thermal comfort prediction using normalized skin temperature in a uniform built environment, Energ Build 159(2018):426-440.

[66] X. Cheng, B. Yang, T. Olofsson, G. Liu, H. Li, A pilot study of online non-invasive measuring technology based on video magnification to determine skin temperature, Build Environ 121(2017):1-10

[67] D. Li, C. C. Menassa, V. R. Kamat, Robust non-intrusive interpretation of occupant thermal comfort in built environments with low-cost networked thermal cameras Appl Energ 251(2019):113336.

[68] J. Kim, S. Schiavon and G. Brager, Personal comfort models-A new paradigm in thermal comfort for occupant-centric environmental control, Build Environ 132(2018)114-124. 
[69] Z. Wang, K. Warren, M. Luo, X. He, H. Zhang, E. Arens, et al. Evaluating the comfort of thermally dynamic wearable devices, Build Environ 167(2020):106443.

[70] K.P. Singh, Occupational health impacts of climate change: current and future ISO standards for the assessment of heat stress, Ind Health 51(1)(2013) 86-100.

[71] G. Havenith, I. Holmér and K. Parsons, Personal factors in thermal comfort assessment: clothing properties and metabolic heat production, Energy Build 34(6)(2002) 581-591.

[72] M. Luo, X. Zhou, Y. Zhu, J. Sundell, Revisiting an overlooked parameter in thermal comfort studies, the metabolic rate, Energ Build 118(2016)152-59.

[73] S.Yasmeen, H. Liu, Y. Wu, B. Li, Physiological responses of acclimatized construction workers during different work patterns in a hot and humid subtropical area of China, J Build Eng 30(2020) 101281.

[74] H. Pallubinsky, B.R.M. Kingma, L. Schellen, B. Dautzenberg, M.A.V. Baak, and W.D.V.M.

Lichtenbelt, The effect of warmth acclimation on behaviour, thermophysiology and perception, Build Res Inform (2017) 1-8.

[75] C. Aubrecht, D. Ozceylan, Identification of heat risk patterns in the US national capital region by integrating heat stress and related vulnerability. Environ Int 56(2013):65-77. 